\title{
DIVULGAÇÃO CIENTÍFICA NAS REVISTAS SCIENTIFIC AMERICAN BRASIL E SUPERINTERESSANTE
}

\section{DIVULGACIÓN CIENTÍFICA EN LAS REVISTAS BRASILEÑAS SCIENTIFIC AMERICAN BRASIL E SUPERINTERESSANTE}

\author{
Cristiane Portela de Carvalho - crisportela14@yahoo.com \\ Doutoranda em Comunicação Social, Programa de Pós-Graduação em \\ Comunicação Social, Universidade Metodista de São Paulo, UMESP
}

\begin{abstract}
Resumo
Analisa-se a divulgação científica nas revistas Scientific American Brasil e Superinteressante por meio das matérias de capa das edições do mês de novembro de 2009, quando tratam do mesmo tema, qual seja "A pílula da inteligência". A investigação parte da premissa de que embora os dois veículos sejam especializados em divulgar ciência ao grande público, cada um possui mecanismos próprios para atingir seus leitores. Para a consecução da investigação proposta utiliza-se a Análise de Conteúdo (AC), vista como método mais apropriado para este tipo de estudo. Conclui-se, portanto, que enquanto a Scientific opta por uma linguagem mais técnica e de maior complexidade para dialogar com seu público-alvo, a Superinteressante usa linguagem direta e de fácil entendimento, mesmo para pessoas que possuem pouca ou nenhuma familiaridade com o tema abordado.
\end{abstract}

\section{Palavras-chave}

Divulgação científica. Revistas especializadas. Scientific American Brasil. Superinteressante.

\section{INTRODUÇÃO}

$\mathrm{Na}$ atualidade, é impossível desconsiderar a necessidade de divulgar ciência à sociedade, visto que parte do interesse da própria ciência é o desenvolvimento do gênero humano. É necessário, porém, afastar o "cientismo" (ou seja, a ciência fechada em si mesma e que é estéril e inútil) e substituí-lo pelo cientificismo, visto como o apoio social e cultural ao trabalho dos cientistas de determinada comunidade. Mas tal apoio está vinculado ao valor que os diferentes 
segmentos sociais dão às pesquisas executadas, à sua concepção acerca da ciência / suas funções / sua utilidade, à garantia de retorno social dos investimentos, pois se acredita que a opinião pública é decisiva na fixação das políticas governamentais em prol da ciência e tecnologia (C\&T).

Desta forma, a mídia, em sua missão, exerce função decisiva ao divulgar os fatos científicos. Proporciona visibilidade à ciência e desperta interesse dos indivíduos para as informações científicas e tecnológicas (ICT), fazendo-os entender que a C\&T é essencial para o crescimento de uma nação, visto que a divulgação da ciência é recurso primordial à consolidação da democracia (CANDOTTI, 2001).

Neste sentido, é oportuno investigar como as revistas Scientific American Brasil e Superinteressante, conceituados veículos de divulgação científica e de grande circulação, no âmbito nacional, tratam da C\&T, com temas recorrentes em conversas cotidianas, como os medicamentos aprimoradores da inteligência e da memória. Quer dizer, é preciso analisar as contribuições dos referidos veículos para a popularização da ciência junto aos leitores.

\section{REVISTAS SCIENTIFIC AMERICAN BRASIL E SUPERINTERESSANTE: ANÁLISE DE CONTEÚDO (AC)}

Objetivando entender quais os mecanismos utilizados pelas revistas Scientific American Brasil e Superinteressante para atingirem seus leitores e sensibilizá-los frente a temas importantes, opta-se pela análise da matéria de capa que ambas tiveram no mês de novembro de 2009. Elas chamam a atenção para as mais recentes descobertas de drogas utilizadas para melhorar 0 funcionamento do cérebro.

Para tal finalidade, recorre-se à técnica da Análise de Conteúdo (AC) como opção metodológica apropriada, pois, como acredita Herscovitz (2007, p. 123), ela "[...] pode ser utilizada para detectar tendências e modelos na análise de critérios de noticiabilidade, enquadramentos e agendamentos". Para este estudo, a AC também se justifica porque "frequentemente utiliza varáveis da mídia, isto é aqueles aspectos do conteúdo que são únicos e característicos do meio utilizado" (EPSTEIN, 2002, p. 18).

\subsection{Análise da Scientific American Brasil}

A revista Scientific American Brasil (número 90, novembro 2009) aborda a questão das drogas utilizadas como aprimoradores da cognição em matéria de capa, intitulada Pílulas da inteligência - o que você deve saber sobre aprimoradores cognitivos, utilizando a cor azul como suporte predominante. Duas cápsulas, nos tons vermelho e branco, representam um nariz e uma boca e formam um rosto, com um par de óculos como complemento. A capa leva a crer que o ser humano é, ou será, essencialmente formado pelas novas drogas que prometem mais memória e desempenho mental superior.

A revista poderia ter colocado na capa um rosto humano, mas optou por formar um rosto com cápsulas. À medida que sugere um "novo homem" feito de 
drogas que o deixarão mais habilitado para viver num mundo agitado $\mathrm{e}$ assustadoramente veloz, como o dos dias atuais, faz crer que esse "novo homem" estará mais disposto e bem preparado para a competição que domina os ambientes de estudo e trabalho.

Com título O cérebro turbinado" e subtítulo "Uma pílula no café da manhã melhorará a concentração e a memória - e fará isso sem causar problemas a longo prazo para a saúde?, a matéria está distribuída ao longo de oito páginas da revista. Logo acima do título são utilizadas, como ilustrações para o texto, várias pílulas (despejadas de um frasco ainda aberto) que, além de desenhos de cérebros, possuem também a gravação $10 \mathrm{MG}$. A idéia é de popularização das pílulas que, de acordo com a matéria, poderão funcionar como aprimoradores cognitivos.

A matéria não é indicada para indivíduos que buscam informações de fácil entendimento sobre o assunto, pois o uso de siglas e de termos específicos requer, mesmo do leitor mais especializado, certa dose de familiaridade com 0 tema tratado. Este fato pode ser observado logo no início do texto com a frase: "o símbolo $\mathrm{H}+$ dos futuristas denomina uma versão aperfeiçoada da humanidade". (p. 36). A palavra cognição também é bastante empregada, como se o leitor já possuísse domínio sobre seu significado, e o texto não procura fornecer explicações que contribuam para facilitar seu entendimento.

Palavras e / ou expressões mais complexas, em muitos casos até tecnicamente bem específicas, também são utilizadas como se fizessem parte do repertório do leitor. Entre elas, destacam-se: aprimoradores neuronais; nootrópicos; modafinil; TDAH [Transtorno do Déficit de Atenção]; metilfenidato; anfetamina; nanotecnologia; nanorrobôs, etc. Explicações, ainda que rápidas e sucintas, além de facilitar a compreensão, poderiam despertar maior curiosidade para aprofundamento do tema ou, simplesmente, despertar mais empenho pela própria leitura, pois o leitor comum se interessaria pelo assunto logo nos primeiros parágrafos.

À medida que o texto assume postura elucidativa, fica mais leve e a leitura, mais prazerosa. É o caso do parágrafo que fala da "memória de longo prazo", explicando que é "o lugar onde as lembranças da infância e das férias do ano passado estão" (p. 39), e também quando cita "memória de trabalho", para, em seguida, esclarecer que é "[...] o rascunho mental onde o cérebro guarda temporariamente um número de telefone". (p. 39). Ou, ainda, quando utiliza a palavra narcolépticos, mas explica que são "vítimas de ataques de sono incontroláveis". (p. 45).

Quando busca mais fundamentação científica para aspectos pontuais, o texto utiliza como fonte de informação a Nature, conceituado veículo de divulgação científica no mundo. Quando cita o uso de estimulantes controlados para fins diferentes da prescrição médica, ou seja, quando os mesmos são utilizados como aprimoradores cognitivos, diz:

Uma pesquisa on-line informal entre os leitores feita pela Nature ano passado mostrou que $20 \%$ dos 1.427 leitores de 60 países que responderam à pesquisa admitiram ter usado metilfenidato, modafinil ou bloqueadores beta (a última moda contra o pânico de 
falar em público). De forma geral, a necessidade de aumentar a concentração foi a razão mais frequentemente citada. (p. 38).

Em outra ocasião, o texto cita a Nature para ressaltar um comentário, publicado no referido veículo, de um grupo de especialistas em ética e de neurocientistas sobre a "[...] hipótese de se abandonar a noção de que as drogas sejam originalmente um tratamento para doenças". (p. 38). A Scientific American Brasil cita, inclusive, o artigo publicado na Nature:

O artigo [da Nature] sugere a possibilidade de fornecer psicoestimulantes a pessoas com mente saudável, visando melhorar seu desempenho, na sala de aula ou de reuniões, desde que se considerem esses medicamentos seguros e eficientes para pessoas sadias. (p. 38).

Embora a Nature seja o veículo mais citado, não é somente ele que é utilizado como embasamento científico para questões delicadas. O texto também cita como fonte o British Medical Journal, mencionando o comentário do bioeticista da University of Manchester, Inglaterra, publicado no referido veículo. Outros conceituados meios de divulgação científica interpares também são referenciados, como os títulos Neuroethics, Psychopharmacology e Science.

Todos os argumentos científicos utilizados na matéria são fundamentados em afirmações de renomados cientistas, que fazem parte de conceituadas instituições de pesquisas de referência mundial. Até sobre 0 uso dos aprimoradores cognitivos, a Scientific American Brasil recorre a cientistas que já fizeram uso desses remédios, dispensando, por conseguinte, a opinião de pessoas comuns que possam ter utilizado as drogas. A matéria cita que o neurocientista Michael S. Gazzaniga (University of California, Santa Bárbara, Estados Unidos da América, EUA) consumia benzedrina nos anos 60 para ajudar nos estudos da faculdade. O texto utiliza, ainda, o depoimento de Jamais Cascio, pesquisador-associado do Institute for the Future, em Palo Alto, California, também dos EUA, que fala sobre sua experiência com o uso do modafinil.

A percepção do aumento no foco cognitivo e na clareza foi uma grande surpresa, mas uma surpresa agradável, lembra Cascio. Minha experiência não foi de ganhar um supercérebro. Em vez disso, eu simplesmente entrava mais facilmente em um estado de fluxo cognitivo, um estado de ser capaz de trabalhar sem distinção. (p. 41).

A matéria também tem o cuidado de apontar correntes ideológicas dissonantes, a fim de que o leitor formule suas próprias conclusões, como no caso da polêmica, envolvendo questões éticas, sobre o uso dos aprimoradores cognitivos. Opiniões divergentes são apontadas pela revista:

John Harris, bioeticista da University of Manchester, na Inglaterra [...] notou que, se o metilfenidato foi considerado seguro para ser usado por crianças, deve ser considerado inócuo o suficiente para o consumo por adultos interessados em turbinar seus cérebros. 
Outros pesquisadores e especialistas em ética questionaram se os medicamentos que modulam os processos mentais algum dia terão um perfil de segurança que justifique sua oferta como a de um analgésico, café ou chá.

Ainda não se calcula o risco existente se houver um grande número de pessoas com acesso a essas drogas. Uma pequena porcentagem provavelmente se viciará e algumas delas poderão até sofrer diminuição do desempenho mental. Essa é a razão pela qual me oponho ao uso generalizado [James Swanson, pesquisador da University of California]. (p. 38 - 39).

A revista, porém, não se limita a mencionar apenas opiniões favoráveis e / ou contrárias ao uso dos aprimoradores, mas revela, também, que "outros cientistas acham esse debate inútil, porque o aumento da inteligência talvez só seja possível com o exercício entediante de estudar até o limite para uma prova de cálculo" (Scientific American Brasil, n. 90, p. 39). Destaca, inclusive, que, para alguns pesquisadores, aprimorar pessoas saudáveis é uma possibilidade remota.

Não me preocuparia muito com as implicações dos aprimoradores cognitivos nas pessoas saudáveis, porque não há aprimoradores cognitivos com os quais se preocupar, resume Rusiko Bourtchouladze, autor de um livro popular sobre a ciência da memória e pesquisador que contribuiu para o trabalho que deu 0 Prêmio Nobel para Eric R. Kandel em 2000. Também ainda é muito cedo para falar sobre o aprimoramento cognitivo; essas drogas podem nem existir durante nossa vida. Há muito barulho sobre esse assunto. (p. 39).

Quando questões econômicas são envolvidas, a matéria também assume postura de alertar o leitor sobre os interesses comerciais que atraem a fabricação e o uso de remédios. Estes, em muitos casos, não foram desenvolvidos especialmente como aprimoradores da cognição, mas fabricados e aprovados para outros propósitos.

Um candidato recentemente testado em estágio avançado para as disfunções cognitivas da doença de Alzheimer, por exemplo, foi desenvolvido na Rússia com um anti-histamínico para a febre do feno; mais tarde, percebeu-se que possui propriedade antidemência. Um mercado potencialmente tentador levou algumas empresas a seguir caminhos não ortodoxos, com a reformulação de um medicamento fracassado ou sem testes clínicos completos, vendido como suplemento alimentar ou como "alimento médico", categoria com regulamentação mais frouxa. ( $p$. 45). 
Muitas vezes, a indústria farmacêutica consegue driblar até mesmo importantes agências reguladoras de alimentos e medicamentos. Segundo a matéria, foi assim que a Cephalon, fabricante do modafinil, conseguiu permissão da Food and Drug Administration (FDA), a agência reguladora norte-americana, "[...] para comercializar essa substância para trabalhadores noturnos, grupo muito maior que os narcolépticos (vítimas de ataques de sono incontroláveis) para os quais originalmente havia sido aprovada". (p. 45).

No que tange aos recursos gráficos, a matéria utiliza sete ilustrações para explicar questões de destaque. Logo no primeiro quadro, intitulado Conceitoschave (p. 37), os editores explanam, sucintamente, o uso dos aprimoradores por estudantes universitários e executivos, bem como a formação de duas correntes de cientistas, uma favorável e outra contrária ao uso desses medicamentos.

A segunda ilustração, Para que melhorar? (p. 38), engloba um gráfico, com a projeção do aumento na longevidade entre os anos de 1994 a 2020, e imagens de um estudante e de um executivo, atordoados com seus afazeres. Na página seguinte, o leitor dispõe de um quadro, Riscos dos turbinadores (p. 39), citando alguns medicamentos, seu uso médico, sua eficiência como aprimoradores e os riscos que podem causar.

A quarta ilustração (Como agem dois aprimoradores, p. 40) é bem técnica. Explica como dois pretensos aprimoradores, o metilfenidato e as anfetaminas, atuam no cérebro, alterando, inclusive, a atividade do neurotransmissor dopamina nas sinapses, ou seja, na junção entre os neurônios. Há um desenho de uma atividade sináptica normal e de uma atividade aumentada por drogas. A quinta ilustração, $O$ despertar do guerreiro (p. 41), assim como a primeira, é bem simples e apenas cita que milhões de anfetaminas eram utilizadas como pílulas "despertadoras" durante a Segunda Guerra Mundial, depois que as mesmas foram distribuídas por um oficial médico da Força Aérea Real Britânica a um membro da tripulação de um bombardeiro.

Em O futuro das pílulas (p. 44), sexta ilustração, explicam-se como os fabricantes têm a intenção de desenvolver medicamentos para combater formas distintas de demência. O quadro aborda a classe do medicamento, como funciona cada um dos remédios e seus desenvolvedores. A última ilustração (Como se fosse ontem, p. 45) explana, detalhadamente, como atuam, no cérebro, os medicamentos que aumentam a cognição, agindo em moléculas envolvidas na memória de longo prazo.

A matéria finaliza, porém, com o alerta de que tanto fabricantes como consumidores podem ser acometidos pelo impulso estimulante de melhorar a cognição, mas que é preciso estar atentos para os "[...] riscos inevitáveis de se brincar com o circuito neural que nos permite a noção básica de sermos nós mesmos". (p. 45).

\subsection{Análise da Superinteressante}

Em novembro de 2009, assim como a Scientific American Brasil, a revista Superinteressante, edição 271 , aborda a questão das drogas utilizadas como aprimoradores cognitivos em matéria de capa intitulada $A$ pílula da inteligência. $O$ subtítulo, além de extenso (Mais concentração, mais raciocínio, mais memória. $A$ 
nova geração de drogas pode dar superpoderes ao cérebro. Será que devemos tomá-las? Nosso repórter experimentou. E tem a resposta), faz uma pergunta e sugere uma resposta que instiga a curiosidade do leitor para que o mesmo se reporte ao texto no interior da revista. A Superinteressante também utiliza a cor azul como suporte predominante da capa e adota três cápsulas como ilustração. Apenas as bases das cápsulas possuem a cor vermelha. As partes superiores são transparentes para que sejam visualizados pequenos cérebros dentro das mesmas.

O texto ocupa 10 páginas da revista e mantém o título da capa, $A$ pílula da Inteligência, mas o subtítulo foi alterado: Já existem medicamentos capazes de turbinar o cérebro - para você pensar, estudar e trabalhar mais e melhor. Mas até que ponto é seguro tomá-los? Logo no início, a matéria coloca o depoimento de três indivíduos que fizeram uso dos aprimoradores e todos falam positivamente da experiência. Vale destacar que a revista preserva a identidade dos depoentes com o uso de nomes fictícios. Enquanto a Scientific American Brasil opta, no relato da experiência, pelo depoimento de cientistas que tomaram os medicamentos, a Superinteressante prefere o relato de pessoas comuns.

A Superinteressante tem texto objetivo, claro e de fácil entendimento para o leitor em busca de atrativos que despertem seu interesse pelo tema e não o faça desistir da leitura. Assim, observa-se que a matéria quando faz uso de termos específicos procura logo explicá-los. Por exemplo, quando fala em medicamentos tarja-preta, explica que eles são "desenvolvidos para tratar disfunções neurológicas - mas que em pessoas saudáveis, podem provocar uma espécie de turbo mental: intensificar a atenção, a concentração, a memória ou certos tipos de raciocínio". (p. 64). Em outro momento, acrescenta que os mesmos são de venda e uso controlados.

Palavras como narcolepsia ("um distúrbio que causa sonolência excessiva durante o dia e afeta 0,2 a $0,5 \%$ da população mundial", p. 64); neurogênese ("a produção de novos neurônios no cérebro", p. 69) e hipocampo ("parte do cérebro que - entre outras coisas - coordena o funcionamento da memória", p. 70) são utilizadas, mas com seus devidos esclarecimentos. O texto explica, também, 0 surgimento do metilfenidato:

[...] mais conhecido por seu nome comercial, Ritalin. Esse composto químico é um derivado das anfetaminas, supostamente com efeitos mais leves e controlados. Os cientistas desenvolveram a droga para tratar distúrbio de déficit de atenção, depressão e outras condições médicas. (p. 67).

Expressões bem corriqueiras e de uso popular, como cachola, para se referir à mente das pessoas, também são utilizadas. Até o mal de Alzheimer, doença bastante conhecida popularmente, recebe explicação técnica detalhada:

É uma doença degenerativa terrível, em que placas de uma substância chamada beta-amiloide começam a se formar no cérebro. O resultado é uma perda significativa da capacidade de gerar memórias. Conforme a doença progride, acaba desembocando na demência e, por fim, na morte. (p. 68). 
A revista tenta criar uma proximidade e familiaridade com o leitor, por meio de frases ou expressões como: "você já deve ter ouvido falar, as anfetaminas são estimulantes fortíssimos"; "olha só esta" (p. 69); "monte de gente" (p. 69); "passo de tartaruga". (p. 69). Ou ainda quando fala das ampaquinas, drogas que ajudarão a reduzir o impacto do mal de Alzheimer, auxiliando no fortalecimento dos sistemas cerebrais ligados à memória:

E as mais promissoras [para o tratamento de Alzheimer] são as ampaquinas, que parecem reforçar as respostas dos neurônios a um neurotransmissor chamado glutamato (antes que você pergunte: não, não é o mesmo glutamato do tempero Aji-No-Moto e dos pratos da culinária chinesa). (p. 68).

O texto da Superinteressante tem uma maneira bem peculiar de "dialogar" com o leitor: lançando perguntas e respondendo-as, mas, sobretudo, estimulandoo a refletir sobre o assunto, para que ele próprio seja capaz de emitir conclusões. Percebe-se isto logo no subtítulo da capa: "Será que devemos tomá-las? Nosso repórter experimentou. E tem a resposta". Outros questionamentos surgem ao longo do texto:

Será que, como acontece em tantos casos que envolvem a indústria farmacêutica, não existe um exagero nisso tudo? Será que, com o uso contínuo, a longo prazo, drogas como o modafinil não podem fazer mal? E será que é uma boa idéia mexer com a química do cérebro? (p. 65).

Como ficam as pessoas que não têm dinheiro para comprar a droga, ou simplesmente não querem tomá-la? Como promover umas disputa justa, no vestibular ou em uma entrevista de emprego, entre pessoas que tomam e não tomam pílulas para o cérebro? (p. 70).

A Superinteressante mantém a preocupação de tornar as citações diretas assimiláveis para o leitor comum, ou seja, são afirmações sem muitas palavras técnicas. Em alguns casos, opta mesmo por esmiuçar a afirmação do cientista:

Um estudo feito no King's College, em Londres, descobriu que o modafinil funciona de maneiras diferentes em pessoas diferentes. "Nossos resultados indicam que o QI [quociente de inteligência] alto pode limitar a detecção dos efeitos positivos da droga", afirma Delia C. Randall, autora da pesquisa. Traduzindo: ele faz mais efeito nas pessoas menos inteligentes. (p. 71).

A Nature também é citada, embora uma única vez, como fonte de legitimação sobre o uso dos remédios que funcionam como aprimoradores cognitivos. A matéria cita um estudo recém-publicado na Nature, revelando que 
" $25 \%$ dos universitários tomam ou tomaram algum tipo de remédio para tentar aumentar seu desempenho cognitivo". (p. 64).

O texto da Superinteressante apresenta argumentos favoráveis e contrários ao uso dos aprimoradores, embora os três depoimentos que abrem a matéria sejam de usuários que se sentiram bem ao ingerir os medicamentos. Ainda que a opinião favorável ao uso dos remédios seja recorrente no texto, a revista tem a preocupação de alertar o leitor para riscos e efeitos colaterais causados pelas drogas, as quais, na maioria das vezes, são produzidas para outras finalidades. Neste caso, a matéria, assim como a Scientific American Brasil, também cita o uso do antialérgico chamado dimebolina, a priori criado por cientistas russos para combater a chamada febre do feno, como "aprimorador mental excepcional", pois "[...] estudos preliminares sugerem que ele melhora o desempenho de voluntários em testes cognitivos, além de deixá-los mais despertos e atentos". (p. 69).

As questões econômicas merecem destaque da Superinteressante graças a comentários sobre a indústria farmacêutica, que usa todos os meios na tentativa de produzir medicamentos que alterem positivamente o funcionamento do cérebro. A revista também lança alguns argumentos. Estes, além de servirem como alerta, envolvem sérias preocupações sociais.

Ao tentar criar uma geração superinteligente de humanos, corremos o risco de terminar com 6 bilhões de toupeiras. Mas, mesmo que todos esses temores se mostrem infundados, ainda restará a preocupação social. E ela talvez seja a pior de todas. Imagine o seguinte cenário. Os avanços da ciência levam à criação de uma droga que aumenta a inteligência e não apresenta nenhum risco ou efeito colateral, seja de curto ou de longo prazo. É a pílula perfeita. Mas, como todas as invenções da indústria farmacêutica, custa caro. Como ficam as pessoas que não têm dinheiro para comprar a droga, ou simplesmente não querem tomá-la? Como promover uma disputa justa [...] entre pessoas que tomam e não tomam pílulas para o cérebro? (p. 70).

A matéria, porém, destaca que, da mesma forma que as pílulas da inteligência podem gerar desigualdades sociais, também podem ajudar a reduzilas. De acordo com um estudo do King's College de Londres, o modafinil funciona de maneiras diferentes em pessoas diferentes, ou seja, a droga faz mais efeito nas pessoas menos inteligentes, assim, "[...] as pílulas da inteligência poderiam aproximar os menos favorecidos intelectualmente da média da população". ( $p$. 71).

Quanto às ilustrações, a Superinteressante utiliza quatro fotos, dois gráficos e um quadro com o relato da semana em que o repórter tomou 0 modafinil. Na primeira foto, o contexto é de um ambiente de trabalho, em que estão três indivíduos, mas apenas um deles apresenta a cabeça com tamanho aumentado, justamente aquele homem que, como sugere a legenda, olha para 0 computador e acha "um relatório lindo e um Excel encantador". Na segunda foto, o contexto é de descontração. Três mulheres se divertem, mas apenas uma delas possui a cabeça com proporções avantajadas, logo aquela que, de acordo com a legenda, afirma: "[...] o Governo finalmente desindexou a dívida mobiliária federal". A penúltima foto apresenta um rapaz, também com cabeça de tamanho 
avolumado, emendando a leitura do clássico Ulisses com um DVD [Digital Video Disc] do Bergman, ainda de acordo com a legenda, e achando tudo muito divertido. A última foto mostra uma sala de aula em que apenas o aluno que possui a cabeça com tamanho maior que a dos outros é capaz de responder a uma pergunta da professora e ainda afirma que "essa é fácil", conforme mostra a legenda.

O primeiro gráfico divide as drogas por grupos: os antipsicóticos, os estimulantes, os calmantes e os alucinógenos. Dentro de cada um dos grupos, as substâncias são reunidas novamente de acordo com propriedades e usos semelhantes. O segundo gráfico explica, detalhadamente, o uso original e os efeitos colaterais de nove drogas, bem como a atuação direta de cada uma delas no aprendizado, na concentração e na memória. Os recursos gráficos utilizados pela Superinteressante são bem mais simples e de fácil entendimento do que os utilizados pela Scientific American Brasil.

Recorrendo a um recurso que predomina ao longo do texto da Superinteressante, no caso, os questionamentos, a matéria termina com uma pergunta para reflexão do leitor: "[...] será que o mundo precisa de alguma coisa que faça as pessoas se fechar em si mesmas para trabalhar ainda mais?" (p. 71).

\section{CONSIDERAÇÕES FINAIS}

Os resultados deste estudo revelam, grosso modo, que embora as revistas Scientific American Brasil e Superinteressante tenham tratado de temas semelhantes nas matérias de capas de novembro de 2009, o fizeram de modos diferentes. Enquanto a Scientific opta por linguagem mais técnica e de maior complexidade para o leitor comum, a Superinteressante usa linguagem direta e de fácil entendimento para as pessoas que possuem pouca ou nenhuma familiaridade com o tema. De forma sucinta, seguem as principais inferências da análise:

- As duas revistas utilizam como fonte de informação cientistas de conceituadas instituições de pesquisas de referência mundial. Enquanto a Scientific American Brasil usa 20 citações diretas (aquelas que citam literalmente a fonte) em matéria com oito páginas, a Superinteressante utiliza apenas seis citações diretas em matéria de 10 páginas.

- Não há, em nenhuma das duas publicações, depoimento de cientista brasileiro.

- Os dois veículos analisados usam a Nature, conceituado veículo de divulgação científica mundial, para fornecer mais fundamentação científica a seus leitores. A Superinteressante, porém, utiliza apenas aquele veículo como fonte de informação, citando-o uma única vez, enquanto a Scientic American Brasil usa também o British Medical Journal e as revistas Neuroethics, Psychopharmacology e Science. 
- Tanto a Scientific American Brasil como a Superinteressante têm o cuidado de apresentar a opinião de cientistas favoráveis e opositores ao uso dos aprimoradores cognitivos, para que o leitor tire suas conclusões.

- Quando tratam de questões econômicas, as duas revistas assumem postura de alerta sobre os interesses comerciais que envolvem a fabricação e o uso de remédios que, em muitos casos, não foram desenvolvidos especificamente como aprimoradores da cognição, mas, sim, fabricados e aprovados com outras finalidades. A Scientific American Brasil é mais contundente a este respeito.

- Tanto a Scientific American Brasil como a Superinteressante incluem sete ilustrações como suporte ao texto. A Superinteressante, porém, faz uso de quatro fotos, enquanto a Scientific utiliza apenas uma foto.

- Enquanto a Scientific American Brasil opta pelo depoimento de cientistas que tomaram os aprimoradores cognitivos e contam suas experiências, a Superinteressante prefere o relato de pessoas comuns, inclusive, destaca, num quadro, as impressões do dia-a-dia do jornalista da revista que tomou modafinil durante uma semana.

- A Superinteressante, na tentativa de criar mais proximidade e familiaridade com o leitor, faz uso de frases e / ou expressões como: "você já deve ter ouvido falar"; "olha só esta"; "monte de gente"; "passo de tartaruga". Emprega, também, palavras de apelo popular como: cachola (para se referir à mente das pessoas), toupeiras e bobeira. Isto pode ser explicado pelo próprio público para o qual a revista se destina, ou seja, de menor poder econômico do que os leitores da Scientific American Brasil.

\section{REFERÊNCIAS}

BARDIN, L. Análise de conteúdo. Lisboa: Ed. 70, 1977.

CANDOTTI, E. Divulgação e democratização da ciência. Ciência e Ambiente, Santa Maria, v. 23, p. 5-13, jul. / dez. 2001.

EPSTEIN, I. Divulgação científica: 96 verbetes. Campinas: Pontes, 2002.

FONSECA JÚNIOR, W. C. da; Análise de Conteúdo. In: DUARTE, J.; BARROS, A. (Org.). Métodos e técnicas de pesquisa em comunicação. 2. ed. 3. reimpr. São Paulo: Atlas, 2009. p. 280-304.

HERSCOVITZ, H. G. Análise de Conteúdo em jornalismo. In: LAGO, C.; BENETTI, M. (Org.). Metodologia de pesquisa em jornalismo. Petrópolis, RJ: Vozes, 2007. 
NOGUEIRA, S. A pílula da inteligência: já existem medicamentos capazes de turbinar o cérebro - para você pensar, estudar e trabalhar mais e melhor. Mas até que ponto é seguro tomá-los? Superinteressante, São Paulo, ed. 271, p. 62-71, nov. 2009.

STIX, G. O cérebro turbinado: uma pílula no café da manhã melhorará a concentração e a memória - e fará isso sem causar problemas a longo prazo para a saúde? Scientific American Brasil, São Paulo, n. 90, p. 36-45, nov. 2009.

\title{
Title
}

Scientific disclosure in Scientific American Brasil and Superinteressante magazines.

\begin{abstract}
This research analyzes the scientific disclosure at Scientific American Brasil and Superinteressante magazines which had, as the cover of their November 2009 edition, a report about the same subject: "The intelligence pill". This investigation is based on the fact that, although both magazines are specialized on scientific disclosure to the general public, each one of them has their own means to reach the target audience. The research was conducted by using the Content Analysis (CA), which is considered to be the best method for this kind of study. It is concluded that Scientific American chooses a more complex and technical language, while Superinteressante uses a direct and easy to understand language, which is intended to reach readers with little or even no familiarity with the mentioned subject.
\end{abstract}

\section{Keywords}

Scientific disclosure. Specialized magazines. Scientific American Brasil. Superinteressante.

\section{Título}

Divulgación científica en las revistas brasileñas Scientific American Brasil e Superinteresante.

\section{Resumen}

Este artículo analiza la divulgación científica de las revistas brasileñas Scientific American Brasil y Superinteressante a través de los textos de las portadas de las ediciones de noviembre de 2009, cuando tratan el mismo tema: "La Píldora de la Inteligencia". La investigación parte de la premisa de que, aunque las dos revistas sean especializadas en la difusión de la ciencia al público en general, cada una posee sus propios mecanismos para llegar a sus lectores. Para alcanzar los fines propuestos en la investigación, la investigación usa el Análisis de Contenido (AC), considerado como el método más adecuado para este tipo de estudio. Los resultados prueban que mientras la Scientific American Brasil opta por un lenguaje más técnico y más complejo para comunicarse con su público, la Superinteressante utiliza un lenguaje directo y comprensible, incluso para las personas que tienen poca o ninguna familiaridad con el tema estudiado.

\section{Palabras clave}


Divulgação científica nas revistas Scientific American e ... Cristiane Portela de Carvalho

Divulgación Científica. Revistas Especializadas. Scientific American Brasil. Superinteressante.

Recebido em: 31/05/2010

Aceito em: $28 / 00 / 2010$ 